\title{
O ensino da estratégia na graduação: resultados de uma experiência
}

\author{
The undergraduate teaching strategy: results of an experiment
}

Mirian Magnus Machado[a], Dirceu Rodrigues Dias ${ }^{[b]}$, Roberto Carlos Klann ${ }^{[c]}$

[a] Doutoranda em Ciências Contábeis e Administração na Universidade Regional de Blumenau (Furb), Blumenau, SC - Brasil, e-mail: mirianmagnus@gmail.com

[b] Mestrando em Ciências Contábeis e Administração na Universidade Regional de Blumenau (Furb), Blumenau, SC - Brasil, e-mail: dr.dias@terra.com.br

[c] Doutor em Ciências Contábeis e Administração, professor titular do Programa de Doutorado em Ciências Contábeis e Administração da Universidade Regional de Blumenau (Furb), Blumenau, SC - Brasil, e-mail: rklann@furb.br

\section{Resumo}

O estudo analisa as contribuições de uma metodologia de ensino para aprendizagem da Gestão Estratégica dos alunos em um Curso de Administração de uma Instituição de Ensino Superior. A necessidade de conciliar os estudos e os compromissos profissionais desafia o professor a trazer conteúdos que permitam refletir sobre o conhecimento na prática. Ainda, o ensino da Gestão Estratégica vem ganhando força em muitos estudos da área. Outro desafio, principalmente em instituições particulares, é o acesso dos alunos a materiais científicos como artigos de congressos e revistas. $\mathrm{O}$ artigo relata um experimento de uma metodologia de ensino utilizada em uma disciplina de Gestão e Planejamento Estratégico II. A pesquisa foi caracterizada neste estudo como exploratória, qualitativa pela análise do conteúdo. Os resultados do experimento e as principais contribuições foram descritas a partir da entrevista com o professor. Evidenciou-se como conteúdo de maior facilidade e aprendizado o Isomorfismo e a Vantagem Competitiva Sustentável.

Palavras-chave: Ensino. Administração. Estratégia.

\section{Abstract}

This paper analyzes the contributions of a teaching methodology for Strategic Management learning of students in a Business course of an Institution of Higher Education. The need to combine studies with professional commitments challenges the teacher to bring contents that so you can reflect on the knowledge in practice. Still, the teaching of strategic management has been gaining strength in terms of studies that address this issue. Another challenge, especially in private institutions is the students' access to scientific materials, for example, articles in journals and conferences. The paper reports an experiment of a teaching methodology in a course of strategic management and planning II. The research was characterized in this study as exploratory, qualitative analysis of the content. The results of 
the experiment and the main contributions has been discussed from the interview with the teacher. It became clear as the content of learning and ease the Isomorphism and Sustainable Competitive Advantage.

Keywords: Teaching. Administration. Strategy.

\section{Introdução}

A Gestão Estratégica é predominante no contexto organizacional e é inerente aos diversos cursos de graduação em Administração do Brasil. 0 ensino de Administração requer que os professores atuem com métodos de ensino que motivem o aluno ao pensamento crítico-reflexivo (BERTERO, 2006). Para tanto, Marion e Marion (2006) reforçam que o professor seja um compositor de métodos e saiba identificar formas diferentes das tradicionais (aulas expositivas). Os alunos de Administração no Brasil possuem como característica latente o fato de serem estudantes-trabalhadores, ou seja, têm de conciliar seus estudos com compromissos profissionais (BERTERO, 2006).

Na perspectiva de Merriam e Cafarella (1999), a aprendizagem de adultos deve sofrer mudanças em suas metodologias e práticas de ensino. Esse é um dos fatores de maior ocorrência nos preceitos teóricos acerca da aprendizagem de adultos. De acordo com Knowles (1980), o educador de adultos deve ter a função de explorar suas práticas educacionais ao aplicá-las aos alunos, que são pessoas maduras. Essa prática deve estar em harmonia com as necessidades e satisfação dos alunos, com a missão da instituição de ensino e com as exigências da sociedade. O papel do professor está no agir não somente como um professor, mas sim como um facilitador da aprendizagem. Beavers (2009) comenta a dificuldade de conscientizar os alunos adultos e de deixar clara essa dinâmica no início das atividades acadêmicas.

A partir de uma experiência de ensino realizada com alunos do oitavo semestre na disciplina de Gestão e Planejamento Estratégico II em uma IES particular, adotando a metodologia de seminários, relacionando diversas teorias extraídas de artigos científicos, define-se a questão problema do estudo: quais as contribuições de uma metodologia de ensino para aprendizagem da gestão estratégica dos alunos do Curso de Administração de uma instituição de Ensino Superior?

Dentre os temas estudados na disciplina em análise podem-se citar: Teoria do Desenvolvimento Econômico (Inovação), com base em Schumpeter
(1997); Teoria Institucional - Isomorfismo, com base no autor Selznik (1996); Visão Baseada em Recursos, com base em Barney (1991); Monitoramento do Ambiente, fundamentado em Aaker (1983); Vantagem Competitiva Sustentável, com base nos autores Porter (1980) e Barney (1991); Forças competitivas de Porter, com base em Porter (1980); Teoria dos Stakeholders, com base em Freeman; (1984); Teoria das Redes, fundamentado em Jarillo (1988); Teoria da Legitimidade, com base nos autores Dimaggio e Powell (2005). De acordo com abordagem dessas teorias, e as possibilidades de ensino, se delineia o objetivo da pesquisa: analisar as contribuições de uma metodologia de ensino para aprendizagem da Gestão Estratégica dos alunos do Curso de Administração de uma instituição de Ensino Superior de Blumenau (SC).

O estudo se justifica pela importância de apresentar uma estratégia de ensino para o curso de Administração. 0 relato dessa experiência promove a disseminação de novas técnicas de ensino e formas de manter o aluno em sala e promover uma discussão com feedback. Novos estudos poderão ser realizados; essa experiência também pode ser replicada em outras disciplinas para saber como se comportam alunos e desenvolvimento do conteúdo.

\section{Fundamentação teórica}

A educação ou aprendizagem de adultos desenvolve-se melhor quando são consideradas as especificidades de contextos sociais dos envolvidos. Lindeman (1926) refere-se à aprendizagem para adultos ao dizer que o processo educacional é infinito, pois a aprendizagem se dá a partir de experiências conjuntamente vivenciadas, discutidas e refletidas sobre os conhecimentos do grupo. 0 mundo dos adultos e a maturidade concernem à consciência da existência de limites, que podem ser substanciados pelo processo de aprendizagem.

Lindeman (1926) reflete sobre preceitos filosóficos de John Dewey nas obras How we think (1910) e Democracy and education (1916). 0 referido filósofo também é basilar para a teoria experiencial preconizada 
por Kolb (1984). A teoria experiencial propõe que os alunos possuem estilos de aprendizagem diferentes e podem adquirir conhecimento de diversas maneiras, podendo apresentar preferências nas formas de aprender. Dewey (1916) comenta que o adulto se motiva a aprender quando o cotidiano é retratado dentro de sala de aula. Ao trazer o cotidiano para contexto do ensino, é possível fazer com que o aluno passe por experiências que geram significados à sua vida profissional.

\section{Estratégia}

Ansoff (1991) elabora conceitos de conteúdo estratégico amplamente aceitos. A estratégia, de acordo com o autor, se relaciona à definição de quais produtos e tecnologias a empresa irá desenvolver, onde e para quem os produtos serão vendidos e como a empresa obterá vantagem sobre os concorrentes a partir desse processo.

A amplitude existente na conceituação da estratégia envolve o entendimento de pesquisadores sobre como a organização funciona junto aos seus processos. Como relata Hambrick (1983), a estratégia adota um conceito multidimensional e situacional e isso dificulta um consenso em sua definição. Assim, o estudo de estratégia pode ter diversos relacionamentos com as demais teorias que seguem.

Na sequência são apresentadas algumas teorias, subjacentes ao desenvolvimento deste estudo sobre uma experiência na graduação no ensino de estratégia.

\section{Teoria do Desenvolvimento Econômico}

Schumpeter (1997), um dos percursores da teoria do desenvolvimento econômico, influencia os estudos e pesquisas na área de inovação. Contudo, verifica-se que outros trabalhos e autores também podem ser considerados referências nos estudos sobre o tema de inovação, que continua em expansão.

Zhuang, Williamson e Carter (1999) tratam de questões sobre como conviver com as mudanças e a relação de dependência da sobrevivência das organizações com a sua capacidade de inovar como ponto crucial para a estratégia do negócio.

Escobar (2012) aponta que o desempenho organizacional possui relação significativa e positiva com a orientação empreendedora, a capacidade dinâmica de absorção e a capacidade de inovação.

\section{Isomorfismo}

Para Frezatti et al. (2009 p. 233), o isomorfismo "corresponde à tendência que as organizações possuem em se assemelharem em decorrência de pressões relacionadas ao ambiente externo. Em outras palavras, criarem uma similaridade organizacional".

As leis e regras fazem surgir o isomorfismo coercitivo, ou seja, por meio das estruturas reguladoras (COSER; MACHADO-DA-SILVA, 2004). Para Gimenez, Hayashi Júnior e Grave. (2007, p. 44), "esse resulta de pressões formais e informais exercidas por organizações sobre outras que podem se encontrar em situações de dependência". Outro tipo de isomorfismo é o normativo, que, para Coser e Machado-da-Silva (2004, p. 7), "se concretiza a partir da dinâmica provocada pelas trocas de experiências e ensinamentos oriundos da movimentação ativa de profissionais, consultores, universidades e dirigentes no interior de um campo organizacional".

De acordo com Gimenez, Hayashi Júnior e Grave (2007, p. 44), o isomorfismo mimético "está baseado nas incertezas vindas do ambiente e na observação e imitação de características antes alheias à organização baseadas em organizações tidas como de sucesso". Coser e Machado-da-Silva (2004, p. 9) afirmam que ele "acontece pela observação entre os iguais, de que estão diante de ambientes institucionais semelhantes, provocando no campo organizacional certa ortodoxia nas ações".

Percebe-se, então, a existência de três tipos de isomorfismo - o coercitivo, o normativo e o mimético -, os quais estão intimamente ligados às relações existentes nas organizações e entre as organizações ou com seus stakeholders.

\section{Forças de Porter}

Porter (1980) discursa sobre a estratégia em um modelo denominado de 5 Forças Competitivas. Já a segunda vertente é comentada como Estratégias Genéricas de Negócio, que trata a competitividade em liderança, baixo custo ou diferenciação.

0 modelo das 5 Forças, segundo Brandenburger (2002), revela a atividade essencial do negócio, ao desdobrar a cadeia de valor ou cadeia vertical de atividade econômica a partir dos fornecedores, concorrentes e clientes. Acrescenta e destaca o papel central dos negócios na criação de valor - com enfoque no baixo custo 
ou na diferenciação, além de mostrar a interdependência entre os fornecedores e clientes.

Contrária à visão de Porter (1980), que tem foco no ambiente externo, as estratégias são baseadas nas oportunidades levantadas nesse ambiente. Alguns autores como Penrose (1959), Barney (1991) e Peteraf (1993) defendem a Visão Baseada em Recursos (VBR), que tem o foco voltado para o ambiente interno da organização, a fim de avaliar os seus recursos e competências, utilizando, muitas vezes, o modelo da cadeia de valor de Porter (1980) para auxiliar nessa análise do ambiente interno da firma.

\section{VBR}

De acordo com Barney (1991), o processo de evolução da Teoria da Visão Baseada em Recursos (VBR) mostra que, além dos recursos tangíveis e intangíveis que a empresa pode controlar, as capacidades dinâmicas e as competências essenciais apresentam-se como fonte de vantagem competitiva.

Nessa perspectiva, tem-se a definição de recursos, que, segundo Barney e Hesterly (2007, p. 64) representam "os itens passíveis de controle por parte da empresa, e que possibilitam a obtenção de vantagem competitiva sustentável (VCS) por serem valiosos, raros, difíceis de imitar e de difícil substituição".

Lazzarotti (2012) afirma que a pesquisa e desenvolvimento (P\&D) é o recurso que se sobressai em pesquisas que mensuram a inovação. Sehnem (2011) aponta a capacidade de inovação também como um recurso atrelado a estratégias ambientais, acrescenta ainda outros fatores importantes como recursos humanos, recursos físicos, habilidades administrativas, cultura organizacional e recursos naturais renováveis.

Nessa visão, os recursos podem ser compreendidos como o conhecimento, as competências no processo organizacional ou as informações sobre os quais a empresa tem controle, que corroboram com as estratégias e sua implementação (BARNEY; HESTERLY, 2007).

\section{Monitoramento do ambiente}

Para realização do monitoramento do ambiente, é comum perceber em estudos como o de Kotler e Keller (2006) que o uso de uma análise do ambiente organizacional contribui para tomada de decisão. Para tanto, podem ser utilizados sistemas de informação. É por meio das informações coletadas por operações junto aos colaboradores que as organizações conseguem monitorar o ambiente (AAKER, 1983). Os autores apresentam o processo de monitorar o ambiente de formas distintas, mas com um mesmo fim - subsidiar o gestor na tomada de decisão. Aaker (1983) ressalta que, em termos estratégicos, pode-se perceber que organizações de todos os tipos e tamanhos podem e conseguem monitorar seu ambiente, quando estruturam essa ação dentro das possibilidades de investimentos de suas organizações.

\section{Teoria dos stakeholders}

Stakeholders são descritos como indivíduos ou grupos que influenciam e são influenciados pela organização. 0 poder de influência afeta o desenvolvimento de estratégias e, consequentemente, o desempenho organizacional (HITT et al., 2002). "Em uma visão contratual da firma, são o conjunto de entes interessados nas atividades da firma. Compreendem investidores, gestores, clientes, fornecedores, comunidade, governo e funcionários" (FREZATTI et al., 2009, p. 264).

As expectativas de cada stakeholder são específicas e têm características distintas entre si, de acordo com as suas realidades. Para Hitt et al. (2002), existem três grupos distintos de stakeholders: no de mercado de capitais (composto por acionistas e principais fontes de capital como bancos); no mercado do produto (composto por clientes, fornecedores, sindicatos); e no setor organizacional (composto por empregados gerentes e não gerentes).

Nesse contexto, organizações necessitam se preparar para a gestão dos seus stakeholders, e esse gerenciamento se apresenta como um fator positivo para o desempenho das organizações e deve fazer parte das estratégias organizacionais (PAVÃO, 2012).

\section{Vantagem Competitiva Sustentável}

Para Coyne (1986), a vantagem competitiva (VC) implica em estratégias sobre produtos, sistema de distribuição, atributos e capacidades, com destaque para os hiatos existentes nos respectivos contextos ambientais. Para que as organizações consigam sobreviver, precisam estocar seus recursos para se 
manter competitivas. A vantagem competitiva sustentável é compreendida a partir do momento em que a implantação de determinada estratégia possua valor superior e não alcançável por seus competidores (HITT; IRELAND; HOSKISSON, 2002).

Conforme Hitt, Ireland e Hoskisson (2002, p. 5), "ao alcançar a competitividade estratégica e conseguir explorar a própria vantagem competitiva, a companhia será capaz de alcançar o seu objetivo primário: a obtenção de retornos acima da média".

\section{Redes}

Segundo Jarillo (1988, p. 32), as redes referem-se ao "modo como as organizações podem usar seus gestores e empreendedores para posicionar suas firmas em fortes estâncias competitivas".

Por isso, são ditas como redes estratégicas, pois o foco está em ganhar a vantagem competitiva sustentável sobre os competidores fora da rede. Jarillo (1988) apresenta também os modos que propiciam as redes eficientes, principalmente quando associados aos baixos custos de transação (WILLIAMSON, 1981). As mudanças do ambiente organizacional inserem-se num contexto de risco e confiança para que as transações sejam efetivadas, não importando a forma de governança: discreta, recorrente, relação contratual ou hierárquica (RING; VAN DE VEN, 1992). Barnard (1968 apud JARILLO, 1988, p. 36) afirma que a sustentabilidade de uma rede se dá pela reputação entre as organizações envolvidas num determinado processo. Quando existe reputação, as transações se tornam eficientes e efetivas.

\section{Teoria da Legitimidade}

A Teoria da Legitimidade está atrelada à sobrevivência da organização. Dimaggio e Powell (2005) relacionam a competitividade a questões de poder e legitimação, seja por regulação social ou econômica.

Para legitimarem-se no ambiente, as organizações desenvolvem as ações por influência legal, política, cultural ou social. 0 isomorfismo é "uma ferramenta útil para se compreender a política e o cerimonial que permeiam parte considerável da vida organizacional moderna" (DIMAGGIO; POWELL, 2005, p. 77) que está sendo buscada pelas organizações.

\section{Metodologia}

0 presente estudo se caracteriza como um estudo empírico e quanto ao objetivo classifica-se como uma pesquisa exploratória com abordagem qualitativa (YIN, 2010).

A estratégia de abordagem foi a pesquisa participante, pois envolveram-se na pesquisa a Coordenação do Curso, o professor e todos os alunos matriculados na disciplina de Gestão e Planejamento Estratégico II do Curso de Administração. A experiência narrada nesse estudo apresenta uma prática para estímulo da pesquisa em bases que tragam assuntos relacionados à Administração e que estimulem os alunos de graduação em Administração à leitura de artigos científicos. Além disso, em momentos da experiência, a metodologia apresentada varia entre a Teoria Comportamental, defendida por Skinner (2000), e a Teoria Cognitivista, preconizada por Piaget (2010).

A Teoria Comportamentalista é utilizada como forma de reforço e punição. No caso dessa experiência, os assuntos foram divididos por aluno por meio de sorteio. Todos foram ao laboratório de informática e, na sequência, o professor solicitou que visitassem primeiramente a página da Associação Nacional dos Programas de Pós-Graduação (Anpad) e, depois, o sítio do Google Acadêmico.

Fazendo uso de um computador, cada aluno pesquisou artigos com o assunto sorteado e escolheu um para apresentar aos colegas, com o consentimento do professor. Na sequência, foi sorteada a ordem de apresentação dos artigos. Além disso, o professor aderiu à abordagem comportamental, ao comentar que todos deveriam ler antes o artigo escolhido pelo colega apresentador, pois seria cobrada a participação efetiva na nota sobre a discussão durante a apresentação.

Em relação à Teoria Cognitivista, foi interessante a prática de uma aprendizagem baseada em problemas. Após cada apresentação e discussão, ocorria um fechamento pelo professor, ressaltando aspectos a serem considerados de acordo com cada assunto e que no momento da discussão não foram ressaltados ou foram interpretados erroneamente. Feito isso, os alunos reuniram-se em grupos e, sobre o conteúdo apresentado, precisavam criar a técnica denominada pelo professor de Contexto-PerguntaResposta. Nessa técnica, os alunos precisavam criar uma pergunta que inter-relacionasse o assunto com a área da Gestão Estratégica e outros textos escolhidos que avançavam no decorrer dos dias de aula. 
Os alunos encaminhavam o texto com pergunta e resposta para o e-mail do professor, que então corrigia e postava no ambiente acadêmico, para que todos pudessem ter acesso ao conteúdo elaborado por seus pares. Além disso, o professor realizou essa ação, pois os textos seriam base para uma avaliação individual com consulta, em que uma das perguntas seria escolhida para a prova.

Quanto à coleta de dados, foram utilizados dados secundários que são os materiais produzidos pelos alunos durante o semestre letivo de julho a novembro de 2011, e foi preparado também um roteiro semiestruturado, instrumento adequado para as entrevistas em profundidade, aplicado ao professor da disciplina ao final do semestre, em novembro de 2011 (GODOI; MATTOS, 2006).

Foi realizada análise de conteúdo do material produzido pelos alunos em momentos da atividade planejada e as contribuições se deram a partir de uma entrevista realizada com o professor da disciplina Gestão e Planejamento Estratégico II. De acordo com Bardin (2002), a análise de conteúdo é um conjunto de técnicas que investigam as comunicações, mensagens e ou conteúdos, nesse caso explicitadas na entrevista do professor e na análise do material dos alunos.

A técnica de análise se deu pelos dados secundários do material produzido pelos alunos. Além disso, houve uma categorização dos temas, que, após elaboração de uma matriz quadrada, foram contemplados para identificar as relações entre os temas. Para tanto, o software UCINET subsidiou tal tratamento. Para a entrevista, preferiu-se a técnica da hermenêutica dialética, em que são apresentadas literalmente as respostas do roteiro de entrevista.

\section{Resultados}

Aplicação de novo método de ensino

Conforme dinâmica apresentada em sala, podem ser encontrados no Quadro 1 as estruturas dos temas sorteados para cada aluno, o artigo correspondente escolhido por ele e uma sinopse sobre esse trabalho.

Os artigos escolhidos pelos alunos obtiveram o aval do professor. A ordem das apresentações deveria seguir conforme exposto no Quadro 1. Entretanto, mudanças ocorreram em virtude de uma catástrofe que ocorreu na cidade. Nesse caso, a empresa de um aluno foi afetada pela enchente, o que fez com que a ordem das apresentações tivesse de ser alterada. Vale ressaltar que, devido ao tempo, houve uma mudança de datas e a última apresentação ocorreu apenas pela discussão do professor em sala, pois o aluno não conseguiu comparecer naquele dia devido a problemas familiares.

Em cada encontro ocorreu a apresentação de um aluno, juntamente com a discussão entre todos. De forma a garantir a leitura por todos os alunos, o professor comentou que parte da nota seria dada pelas discussões em sala, parte pela apresentação e parte pela formação de um contexto pergunta e resposta, inter-relacionando os textos conforme avanços das datas de apresentação. À medida que o aluno apresentava o artigo escolhido, o professor fazia inferências para estimular a apresentação de todos. No Quadro 2 apresenta-se o exercício contexto-pergunta-resposta com as questões elaboradas pelos próprios alunos.

Apesar de constarem algumas perguntas e itens relacionados em cada questão, é preciso ressaltar que não se encontram questões relacionadas aos temas

Quadro 1 - Temáticas e artigos discutidos nas disciplinas

\begin{tabular}{cll}
\hline Aluno & \multicolumn{1}{c}{ Tema sorteado } \\
\hline A & Teoria do Desenvolvimento Econômico (Inovação) & Costa (2006) \\
B & Isomorfismo & Coser e Machado-da-Silva (2004) \\
C & Visão Baseada em Recursos & Pavão, Sehnem e Hoffmann (2011) \\
D & Vantagem Competitiva Sustentável & Campos e Barbosa (2001) \\
E & Monitoramento do Ambiente & Xavier e Cancellier (2008) \\
F & Forças Competitivas de Porter & Schneider et al. (2009) \\
G & Teoria dos Stakeholders & Mainardes et al. (2011) \\
H & Redes & Cunha (2008) \\
I & Teoria da Legitimidade & Rossoni e Mendes-da-Silva (2011) \\
\hline
\end{tabular}

Fonte: Dados da pesquisa. 
Quadro 2 - Questões do contexto-pergunta-resposta e temas relacionados

\begin{tabular}{|c|c|}
\hline Questões do Contexto-Pergunta-Resposta & Temas \\
\hline $\begin{array}{l}\text { Como uma empresa pode alavancar suas vendas, aumentar a lucratividade realizando } \\
\text { uma ruptura no fluxo circular econômico tendo como desafio um cenário de incertezas? }\end{array}$ & Teoria do Desenvolvimento Econômico \\
\hline $\begin{array}{l}\text { Conforme Schumpeter, as inovações no sistema econômico não aparecem a partir } \\
\text { de uma necessidade dos consumidores. Para ele, é o produtor, no caso o empresário, } \\
\text { quem promove essas mudanças, despertando as necessidades em seus clientes. Como o } \\
\text { produtor pode despertar essa necessidade de consumo em seus clientes e de que forma } \\
\text { isso pode influenciar no desenvolvimento econômico na visão do autor? }\end{array}$ & Teoria do Desenvolvimento Econômico \\
\hline $\begin{array}{l}\text { A partir do artigo, de que forma os empresários conseguem se manter ativos em- } \\
\text { pregando a Teoria do Desenvolvimento Econômico, sendo que a globalização e a } \\
\text { evolução econômica geram mudanças rápidas e constantes? }\end{array}$ & Teoria do Desenvolvimento Econômico \\
\hline $\begin{array}{l}\text { Como uma empresa que adota ações isomórficas consegue se legitimar no mercado, } \\
\text { sendo que o cliente já está habituado ao produto da organização focal? Qual tipo de } \\
\text { isomorfismo seria mais adequado a ser utilizado? Como ela pode se utilizar dele para } \\
\text { quebrar o fluxo circular? }\end{array}$ & $\begin{array}{l}\text { Teoria do Desenvolvimento Econômico } \\
\text { +lsomorfismo }\end{array}$ \\
\hline $\begin{array}{l}\text { A teoria da Visão Baseada em Recursos como Vantagem Competitiva em Organizações } \\
\text { explica que os recursos internos das organizações são suas vantagens competitivas e } \\
\text { podem ser identificados por meio do método VRIO, possuindo relação com o SWOT da } \\
\text { organização na parte de verificação dos pontos fortes e fracos. De que maneira pode-se li- } \\
\text { gar essa teoria às vistas anteriormente, a Teoria do Desenvolvimento Econômico e a Teoria } \\
\text { de Isomorfismo, e como isso se torna uma vantagem para a organização? }\end{array}$ & $\begin{array}{l}\text { Teoria do Desenvolvimento Econômico } \\
\text { + Isomorfismo + Visão Baseada em } \\
\text { Recursos + Vantagem Competitiva } \\
\text { Sustentável }\end{array}$ \\
\hline $\begin{array}{l}\text { Diante do cenário atual, no qual a estratégia das empresas é predominantemen- } \\
\text { te isomórfica, isso quando relacionado à abertura de novos empreendimentos, e } \\
\text { sabendo-se que o desenvolvimento se dá pela quebra do fluxo circular proveniente } \\
\text { das combinações de recursos, de que forma as organizações podem gerar vantagem } \\
\text { competitiva sustentável baseada na combinação de seus recursos tanto intangíveis } \\
\text { quanto tangíveis? Como se relaciona com o isomorfismo? }\end{array}$ & $\begin{array}{l}\text { Teoria do Desenvolvimento Econômico } \\
\text { + Isomorfismo + Visão Baseada em } \\
\text { Recursos + Vantagem Competitiva } \\
\text { Sustentável }\end{array}$ \\
\hline $\begin{array}{l}\text { De que forma é possível romper o fluxo circular sem pôr em risco o investimento } \\
\text { inicial do desafio que é abrir o próprio negócio? }\end{array}$ & $\begin{array}{l}\text { Visão Baseada em Recursos + Monitora- } \\
\text { mento do Ambiente }\end{array}$ \\
\hline $\begin{array}{l}\text { Para a empresa tornar-se mais competitiva e para sobreviver no mercado, ela precisa } \\
\text { se adaptar ou gerar as mudanças que ocorrem ao meio envolvente como ferramenta } \\
\text { obrigatória para o sucesso. A partir das } 5 \text { Forças de Porter, como a empresa consegue } \\
\text { obter vantagem competitiva relacionando os recursos ao monitoramento do ambien- } \\
\text { te externo e interno? }\end{array}$ & $\begin{array}{l}\text { Forças competitivas de Porter + Vanta- } \\
\text { gem Competitiva sustentável + Monito- } \\
\text { ramento do Ambiente }\end{array}$ \\
\hline $\begin{array}{l}\text { Como uma organização pode conciliar a RBV com as } 5 \text { Forças Competitivas de Porter } \\
\text { para avaliar o desempenho organizacional e obter vantagem competitiva? }\end{array}$ & $\begin{array}{l}\text { Visão Baseada em Recursos + Forças } \\
\text { competitivas de Porter + Vantagem } \\
\text { Competitiva Sustentável }\end{array}$ \\
\hline $\begin{array}{l}\text { Considerando uma organização que atua no segmento B2B, localizada no sul do } \\
\text { Brasil, com pessoas e profissionais enraizados na cultura europeia, de que modo } \\
\text { poderá alcançar a VCS por meio de redes? Qual a relação da VCS em uma empresa } \\
\text { B2B com textos sobre Schumpeter, Isomorfismo, Monitoramento do Ambiente, Forças } \\
\text { de Porter? }\end{array}$ & $\begin{array}{l}\text { Vantagem Competitiva Sustentável + } \\
\text { Teoria do Desenvolvimento Econômico } \\
\text { + Isomorfismo + Monitoramento do } \\
\text { Ambiente + Forças competitivas de } \\
\text { Porter }\end{array}$ \\
\hline
\end{tabular}

Fonte: Dados da pesquisa. 
stakeholders, redes e legitimidade. Isso porque, após o envio do contexto pergunta-resposta dos alunos para o $e$-mail do professor, o conteúdo desenvolvido pelo grupo era revisado e avaliado. Caso houvesse alterações a serem realizadas, os grupos deveriam retornar com as correções. Entretanto, nem sempre houve retorno. Nesse caso, foi considerado pelo professor apenas o trabalho desenvolvido em sala, ou seja, houve desconto de nota pela não finalização da atividade.

A partir do estabelecimento de uma matriz $6 \times 6$, cada linha e coluna representando uma temática abordada na disciplina, foram transportados os dados ao software UCINET, para identificar as redes formadas entre os temas. De forma a estabelecer uma melhor interpretação da Figura 1, os nós representam cada temática: Teoria do Desenvolvimento Econômico (TDE); Isomorfismo (ISO); Monitoramento do Ambiente (MON); Visão Baseada em Recursos (VBR); Vantagem Competitiva Sustentável (VCS) e Forças Competitivas de Porter (FOR).

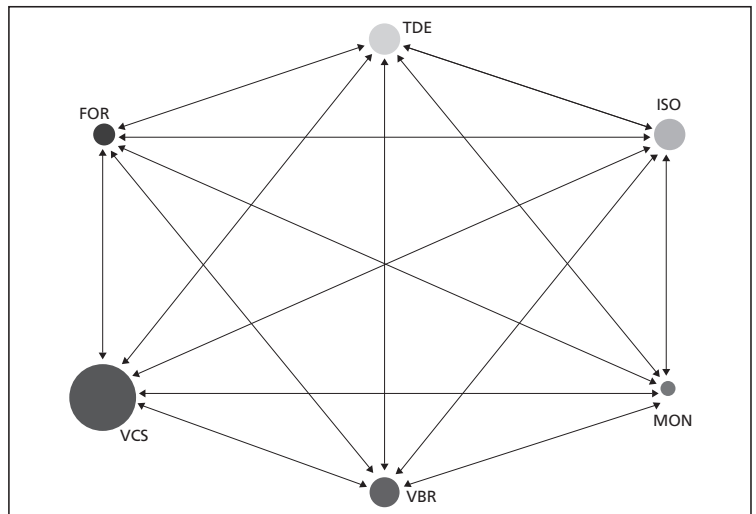

Figura 1 - Relações entre os temas do Contexto-Pergunta -Resposta

Fonte: Dados da pesquisa.

A partir da Figura 1, é possível identificar que todos os temas apresentaram alguma relação com algum outro tema. Isso demonstra que os alunos não analisaram um tema isoladamente das outras temáticas estudadas. Ainda, das atividades recebidas, os temas em que os alunos conseguiram identificar maior relação com os outros foi o tema Vantagem Competitiva Sustentável (VCS), com maior nó da Figura 1. A temática sobre VCS recebeu 14 relações.

Entretanto, a matriz gerada permite identificar que os temas que mais receberam relação um com o outro foram Teoria do Desenvolvimento Econômico e Isomorfismo, perfazendo um total de quatro relações entre si. Acredita-se que isso tenha ocorrido porque os textos dessas duas temáticas são os primeiros trabalhados e apresentados em sala. Talvez por isso figurado por mais tempo como temática das discussões. Ainda na Figura 1 é possível perceber que o monitoramento do ambiente foi o que obteve menos relações.

O professor também elaborou uma avaliação individual com consulta nos textos sobre as apresentadas no Quadro 3.

No Quadro 4 foram apresentadas sete questões. No entanto, a questão 1 era comum a todos os alunos. As questões $2 \mathrm{a}, 2 \mathrm{~b}$ e $2 \mathrm{c}$ eram sorteadas, assim como as questões $3 \mathrm{a}, 3 \mathrm{~b}$ e $3 \mathrm{c}$.

Após a aplicação desse método de ensino, foi realizada a entrevista com o professor. Os resultados são discutidos na sequência.

\section{Percepções do professor}

Para uma melhor estruturação da entrevista, seu roteiro partiu dos fatores Autoavaliação, Corpo Discente, Metodologia e Conteúdo, conforme pode ser observado no Quadro 4.

No concernente à autoavaliação, o professor comenta e referencia experiências e conhecimentos mais orientados à docência. Nesse sentido, ele afirma:

quanto à experiência, sinto-me à vontade para fazer relações entre teoria e prática. 0 tempo de docência e as diversas disciplinas que já trabalhei propiciam fazer e explicar o conteúdo em contextos organizacionais. [...] a academia e a capacitação com o mestrado, doutorado, me permitem aprofundar o conhecimento.

Sobre a didática, o professor comenta que:

inicialmente, houve a conversa com a coordenadora do curso sobre a possibilidade de ampliar o conteúdo da ementa da disciplina, visto que com o doutorado percebeu que o curso poderia ampliar e expandir conhecimentos para assuntos tratados na ciência, principalmente em estudo stricto sensu.

A didática teve como base uma metodologia dialética entre professor e coordenador. Ao adotar prática colaborativa dentro de sala de aula, esse processo 
Quadro 3 - Questões da avaliação

\begin{tabular}{|c|c|}
\hline Questão 1 & $\begin{array}{l}\text { A partir do seu texto, elabore um contexto de pergunta e resposta diferente das realizadas em sala. O seu texto } \\
\text { deverá fazer relação com pelo menos mais dois textos trabalhados em sala. }\end{array}$ \\
\hline Questão 2a & Como a VCS pode ser influenciada a partir da Teoria dos Stakeholders e das Forças Competitivas de Porter? \\
\hline Questão 2b & Sabendo que o Isomorfismo é presente nas estratégias organizacionais, como a VBR se enquadra nesse contexto? \\
\hline Questão 2c & Partindo do texto sobre Teoria do Desenvolvimento Econômico, enquadre os aspectos da Legitimidade. \\
\hline Questão 3a & Como o monitoramento do ambiente pode ser visto junto ao texto disponibilizado de Astley e Van de Ven? \\
\hline Questão 3b & O ambiente organizacional descrito por Astley e Van de Ven possui qual relação sobre o contexto de redes? \\
\hline Questão 3c & Como o voluntarismo descrito por Astley e Van de Ven se efetiva na Gestão do Conhecimento? \\
\hline
\end{tabular}

Fonte: Dados da pesquisa.

Quadro 4 - Roteiro de entrevista com o professor

\begin{tabular}{|c|c|}
\hline Fatores & Questões \\
\hline \multirow{4}{*}{ Autoavaliação } & Como você avalia sua experiência para a disciplina? \\
\hline & Como você avalia seu conhecimento para a disciplina? \\
\hline & $\begin{array}{l}\text { Como foi a proposta de sua didática? Ocorreu igual até o fim? Houve alguma mudança na condu- } \\
\text { ção das atividades? Caso sim, quais foram as implicações dessas mudanças? }\end{array}$ \\
\hline & Como foi seu relacionamento com a turma? \\
\hline \multirow{6}{*}{ Corpo Discente } & Como você avalia os alunos no processo da disciplina? \\
\hline & Como foram em relação a prazos? \\
\hline & Quais foram as principais dificuldades encontradas pelos alunos? \\
\hline & Como se deu aspecto da motivação com os alunos? \\
\hline & Até que ponto havia participação espontânea? \\
\hline & Como os alunos se sentiram com o tema proposto? \\
\hline \multirow{4}{*}{ Metodologia } & Em que momento era explícita a relação conteúdo-disciplina? \\
\hline & Que habilidades pretendia que adquirissem? E o que realmente ficou percebido, em sua opinião? \\
\hline & Quais atitudes dos alunos ficaram mais latentes com essa metodologia? \\
\hline & $\begin{array}{l}\text { Ao final da disciplina, como você acredita que os alunos percebiam a aplicabilidade do conheci- } \\
\text { mento adquirido? }\end{array}$ \\
\hline \multirow{3}{*}{ Conteúdo } & $\begin{array}{l}\text { Entre os temas abordados, qual você acredita que os alunos mais facilmente conseguiram fazer } \\
\text { relação com a disciplina? }\end{array}$ \\
\hline & Entre os temas abordados, qual foi o mais fácil e o mais difícil de trabalhar? Por quê? \\
\hline & Entre os temas abordados, qual tema teve mais e qual teve menos relação? Por quê? \\
\hline
\end{tabular}

Fonte: Dados da pesquisa.

também foi considerado, na visão do professor, para estabelecer um momento de tensão, mas que também fosse de construção, de forma que a apresentação não ocorresse como um monólogo. [...] Deve-se considerar que houve uma pressão em termos de que parte da nota seria pelas discussões em sala.

Percebe-se que, num primeiro momento, a abordagem se deu mais de uma forma comportamental do que propriamente cognitivista. Entretanto, o professor acredita que "a cobrança da nota é importante, pois os alunos não estão acostumados com esse tipo de metodologia e, muito menos, se posicionarem perante outros colegas". Essa forma de condução vai ao encontro dos preceitos de Bertero (2006) e Marion (2006), em que é preciso unir teoria e prática para que o aluno possua competências de um administrador.

O professor salienta ainda que:

Por meio dessa estratégia de ensino, é possível estimular habilidades como apresentação, comunicação, 
liderança e argumentação. Além disso, envolve atitudes relacionadas ao respeito de uma ideia contrária. Já o conhecimento advém das próprias respostas e relações que fazem entre os temas, para que tenham uma visão holística do campo organizacional, no caso da disciplina com a estratégia.

Mesmo com planejamento da aula, houve situações que exigiram do docente um "plano b" para condução da disciplina.

Infelizmente, a cidade foi atingida por uma catástrofe e um de nossos alunos perdeu seu empreendimento, o que fez com que fosse feita uma reengenharia da ordem das apresentações. Outra situação foi a semana acadêmica de administração, mas que conforme palestra feita sobre negócios B2B, os alunos deveriam responder um contexto pergunta resposta alinhando conteúdo da disciplina com o conteúdo da palestra. Mesmo assim, tudo ocorreu tranquilamente, até porque a turma era pequena e então o nosso relacionamento era mais estreito. Além do que, os alunos já haviam cursado duas disciplinas anteriormente comigo.

Um professor deve saber coreografar sua aula e estar preparado para estratégias emergentes. No caso da resposta do professor, há de se inferir que essa didática foi aplicada com uma turma de apenas nove alunos. Uma pergunta agora que se levanta é: será que em um grande grupo o resultado também seria o mesmo?

Outra constatação do professor se deu em relação à correção dos trabalhos pelos alunos: Outro ponto é que os alunos faziam em sala, cumprindo com as exigências da disciplina, mas, ao encaminharem seus papers para o e-mail, eu retornava solicitando alterações e não reenviam.

Por esse motivo, na análise do contexto pergunta e resposta, não constam as áreas Teoria dos Stakeholders, Legitimidade e Redes. Talvez aqui a estratégia mais adequada fosse a de validar o material produzido pelos alunos somente quando postado corretamente no sistema acadêmico da IES.

Sobre a aplicação prática da teoria estudada, o professor destaca:

Era muito interessante ver alunos utilizando termos $e$ conteúdos de teorias que até então não haviam visto $e$ identificando aplicabilidade para tal. Uns alunos se desenvolveram melhor na apresentação, enquanto outros se desenvolveram melhor nas discussões e outros no desenvolvimento do contexto pergunta e resposta.

É possível perceber que, mesmo sendo uma única didática para todos os alunos, cada um evolui de uma forma diferente, isso talvez porque cada aluno possua um estilo de aprendizagem diferente do outro (KOLB, 1984; MARION; MARION, 2006). Outro ponto a ser ressaltado é que o aluno só terá participação ativa quando identificar aplicabilidade para determinado conteúdo em sua vida profissional (MERRIAM; CAFFARELLA, 1999).

Quanto ao conteúdo destaque, observou-se o Isomorfismo e a Vantagem Competitiva Sustentável, conforme apresentado na análise de dados secundários (Tabela 1 e Figura 1), sendo reforçado pelo professor: Talvez pelo fato de que o segundo texto tenha sido o Isomorfismo, ficou mais claro e fácil para os alunos fazerem relação. Além disso, o professor aponta ainda que: a Vantagem Competitiva Sustentável ganhava destaque nas conversas e nos relatórios.

Infere-se aqui que os alunos não trabalharam com obras seminais e sim com estudos correlatos pelas temáticas. Talvez esse possa ter sido um viés para que os alunos aceitassem e entendessem melhor as temáticas, relacionando-as umas às outras.

0 tema de menor relação foi o de Legitimidade. Em virtude de uma mudança de data, uma aluna só cursava a determinada disciplina na quinta-feira de manhã, por isso o professor fez as relações, explicou o tema e entregou um relatório elaborado pela aluna, relacionando com as demais temáticas.

O professor ainda destaca que: no trabalho interdisciplinar que os alunos também deveriam fazer, utilizaram as estratégias de um plano de negócios enquadrando em algumas temáticas. Inclusive outros professores desconheciam tais teorias.

Esse contexto possibilita refletir que a dependência de trajetória de um professor influencia, já que o professor tende a trazer experiências do stricto sensu para dentro de sala de aula.

\section{Conclusões}

0 presente estudo faz referência a obras científicas, que junto à estratégia apresentada pode ser uma maneira de aproximar os alunos do meio científico e não considerar apenas leituras didáticas. Além disso, pode-se perceber que essa estratégia de ensino 
foi aplicada nas últimas fases do curso. Talvez essa prática pudesse ser mais bem explorada em fases iniciais, de forma a incentivar o uso e a leitura de material científico, como artigos de congressos e revistas.

Constatou-se, tanto pelo tratamento de análise de conteúdo no software UCINET quanto na fala do professor entrevistado, que o conteúdo mais facilmente trabalhado foi o Isomorfismo. Aspectos como o tipo de artigo e quantidade de alunos também devem ser considerados, já que não tiveram acesso às obras seminais, ficando essa explicação a cargo do professor. O número reduzido de alunos possibilitou uma maior interação entre alunos e professor.

Outro ponto a destacar é que o professor precisou reestabelecer prazos em virtude de catástrofes e mudanças internas da IES. Isso pode ser visto por um lado positivo, pois no ambiente organizacional o administrador, às vezes, também precisa readequar os prazos e, para isso, precisa ter competências essenciais. Essas competências foram de certa forma mais exploradas do que em um seminário apenas expositivo, que muitas vezes não permite analisar os conteúdos de uma maneira integradora.

Depreende-se que é preciso que o docente esteja preparado e planeje sua aula pensando em possíveis falhas, e que determine antecipadamente o objetivo da aprendizagem com determinada estratégia de ensino.

Conclui-se, de maneira geral, que a experiência relatada no ensino de Administração contribuiu para o uso de material científico dentro de sala de aula, ainda que tentando garantir a presença e proatividade e comprometimento dos alunos. Os resultados foram satisfatórios na percepção do professor ao expor os ganhos obtidos pelos comentários em discussões e montagem de relatórios escritos pelos alunos.

Além disso, sugere-se que outras didáticas sejam adotadas para fins de comparação e que o escopo do estudo seja ampliado com a realização de um focus group com os alunos, que pode proporcionar outra percepção sobre a proposta de ensino.

Este artigo não teve a preocupação de defender ou acusar o método utilizado, mas sim de apresentar possibilidades para estratégias de ensino em sala de aula, nesse caso com a disciplina de Estratégia. Algumas disciplinas podem conseguir mais facilmente desenvolver essa didática, enquanto outras poderão ter maior dificuldade. 0 principal benefício dessa metodologia foi instigar o aluno a pensar no conteúdo com sua prática e demais conteúdos da disciplina.

\section{Referências}

AAKER, D. A. Organizing a strategic information scanning system. California Management Review, v. 25, n. 2, p. 7683. 1983. doi:10.2307/41165007.

ANSOFF, I. A nova estratégia empresarial. São Paulo: Atlas, 1991.

BARDIN, L. Análise de conteúdo. Lisboa: Edições 70, 2002.

BARNEY, J. B. Firm resources and sustained competitive advantage. Journal of Management, v. 17, n. 1, 1991. doi: 10.1177/014920639101700108.

BARNEY, J. B.; HESTERLY, W. S. Administração estratégica e vantagem competitiva. São Paulo: Pearson Prentice Hall, 2007.

BEAVERS, A. Teachers as learners: implications of adult education for professional development. Journal of College Teaching \& Larning, v. 6, n. 7, p. 25-30, nov. 2009.

BERTERO, C. O. Ensino e pesquisa em administração. São Paulo: Thomson, 2006.

BRANDENBURGER, A. Porter's added value: high indeed! Academy of Management Executive, v. 16, n. 2, p. 58-60, 2002. doi:10.5465/AME.2002.7173523.

CAMPOS, R. L.; BARBOSA, F. V. Gestão do conhecimento: o conhecimento como fonte de vantagem competitiva sustentável. In: ENCONTRO NACIONAL DOS PROGRAMAS DE PÓS-GRADUAÇÃO EM ADMINISTRAÇÃO. 2001. Anais... Rio de Janeiro: ANPAD, 2001. p. 1-14.

COSER, C.; MACHADO-DA-SILVA, C. L. Isomorfismo na rede de relacionamentos do espaço social de Videira - SC. In: ENCONTRO NACIONAL DOS PROGRAMAS DE PÓSGRADUAÇÃO EM ADMINISTRAÇÃO, 2004, Rio de Janeiro. Anais... Rio de Janeiro: ANPAD, 2004. p. 1-16.

COSTA, A. B. O desenvolvimento econômico na visão de Joseph Schumpeter. Cadernos IHU Idéias, v. 4, n. 47, p. 1-22, 2006.

CUNHA, J. A. C da. Sobre arranjos produtivos locais e clusters. In: ENCONTRO DE ADMINISTRAÇÃO PÚBLICA E GOVERNANÇA, 2008. Salvador. Anais... Salvador: ANPAD, 2008.

COYNE, K. P. Sustainable competitive advantage - What It Is, What It Isn't. Business Horizons, v. 29, n. 1, p. 54-61, 1986. doi:10.1016/0007-6813(86)90087-X. 
DIMAGGIO, P. J.; POWELL, W. W. A gaiola de ferro revisitada: isomorfismo institucional e racionalidade coletiva nos campos organizacionais. Clássicos. Revista Eletrônica de Administração, v. 45, n. 2, p. 74-89, abr./ jun. 2005.

ESCOBAR, M. A. Relação das capacidades dinâmicas e orientação empreendedora com o desempenho em agências de viagens moderada pelo ambiente organizacional. 2012. 202 f. Tese (Doutorado em Administração e Turismo) - Universidade do Vale do Itajaí, Biguaçu, 2012.

FREEMAN, R. E. Strategic management: a stakeholder approach. Boston: Pitman, 1984.

FREZATTI, F. et al. Controle gerencial - uma abordagem da contabilidade gerencial no contexto econômico, comportamental e sociológico. São Paulo: Atlas, 2009.

GIMENEZ, F. A. P.; HAYASHI JUNIOR, P.; GRAVE P.S. Isomorfismo mimético em estratégia: uma ferramenta para investigação. RAM - Revista de Administração Mackenzie, v. 8, n. 4, p. 35-39. 2007.

GODOI, C. K.; MATTOS, P. L. C. L. Entrevista qualitativa: instrumento de pesquisa e evento dialógico. In: GODOI, C. K.; BANDEIRA DE MELLO, R.; SILVA, A. S. Pesquisa qualitativa em estudos organizacionais: paradigmas, estratégias e métodos. São Paulo: Saraiva, 2006.

HAMBRICK, D. C. Some tests of the effectiveness and functional attributes of miles and Snow's strategic types. Academy of Management Journal, v. 26, n. 1, p. 5-26, 1983. doi: $10.2307 / 256132$.

HITT, M. A.; IRELAND, R. D.; HOSKISSON, R. E. Administração estratégica competitive e globalização. Trad. José Carlos Barbosa dos Santos e Luiz Antonio Pedro Rafael. São Paulo: Pioneira Thomson Learning, 2002.

JARILLO, J. C. On strategic networks. Strategic Management Journal, v. 9, p. 31-41, 1988. doi:10.1002/smj.4250090104.

KNOWLES, M. S. The modern practice of adult education. Englewood Cliffs: Prentice Hall, 1980.

KOLB, D. A. Experimental learning: experience as the source of learning and development. New Jersey: PrenticeHall, Englewood Cliffs, 1984.

KOTLER, P.; KELLER, K. L. Marketing management. 12. ed. Upper Saddle River: Pearson Prentice-Hall, 2006.
LAZZAROTTI, F. Recursos para inovação e desempenho de firmas inovadoras. 2012. $292 \mathrm{f}$. Tese (Doutorado em Administração e Turismo) - Universidade do Vale do Itajaí, Biguaçú, 2012.

LINDEMAN, E. C. The meaning of adult education. New York: New Republic INC., 1926.

MAINARDES, E. W. et al. Um novo modelo de classificação dos stakeholders. In: ENCONTRO DE ESTUDOS EM ESTRATÉGIA. 5., Porto Alegre, 2011. Anais... Rio de Janeiro: ANPAD, 2011. p. 1-13.

MARION, J. C; MARION, A. C. Metodologias de ensino na área de negócios: para cursos de administração, gestão, contabilidade e MBA. São Paulo: Atlas, 2006.

MERRIAM, S.; CAFFARELLA, R. Learning in adulthood: a comprehensive guide. 2. ed. San Francisco: Jossey-Bass, 1999.

PAVÃO, Y. M. P.; SEHNEM, S.; HOFFMANN, V. E. Recursos organizacionais que sustentam a vantagem competitiva em organizações: um estudo multicaso no Paraná. Revista de Administração da Universidade de São Paulo, v. 46, n. 3, jul./set. 2011.

PAVÃO, Y. M. P. A Capacidade de gestão dos stakeholders e o ambiente organizacional: relações e impactos no desempenho das Cooperativas do Brasil. 2012. 225 f. Tese (Doutorado em Administração e Turismo) - Universidade do Vale do Itajaí, Biguaçu, 2012.

PENROSE, E. T. The Theory of Growth of the Firm. London: Basil Blackwell, 1959.

PETERAF, M. A. The cornerstones of competitive advantage: a resource-based view. Strategic Management Journal, v. 14, p. 179-191, 1993. doi:10.1002/smj.4250140303.

PIAGET, J. J. Psicologia e pedagogia: a resposta do grande psicólogo aos problemas do ensino. Rio de Janeiro: Forense Universitária, 2010.

PORTER, M. Competitive strategy: techniques for analyzing industries and competitors. New York: The Free Press, 1980.

RING, P. S.; VAN DE VEN, A. H. Structuring cooperative relationships between organizations. Strategic Management Journal, v. 13, p. 483-498. 1992. doi:10.1002/ smj.4250130702. 
ROSSONI, L.; MENDES-DA-SILVA, W. Nos limites da legitimidade: uma análise do risco no mercado de capitais brasileiro. In: ENCONTRO DE ESTUDOS EM ESTRATÉGIA, 5., Porto Alegre, 2011. Anais... Rio de Janeiro: ANPAD, 2011. p. 1-17.

SCHNEIDER, A. B. et al. Estratégia competitiva: Michael Porter 30 anos depois. Rev. Adm. UFSM, v. 2, n. 2, p. 298326, maio/ago. 2009.

SCHUMPETER, J.A. Teoria do desenvolvimento econômico: uma investigação sobre lucros, capital, crédito, juro e o ciclo econômico. São Paulo: Nova cultural, 1997.

SELZNIK, P. Institutionalim old and new. Administrative Science Quarterly, v. 41, n. 2, p. 270-277, 1996. doi:10.2307/2393719.

SEHNEM, S. Análise dos recursos, estratégias ambientais e desempenho das organizações. 2011. 215 f. Tese (Doutorado em Administração e Turismo) - Universidade do Vale do Itajaí, Biguaçu, 2011.

SKINNER, B. F. Ciência e comportamento humano. São Paulo: Martins Fontes, 2000.
XAVIER, W. G.; CANCELLIER, E. L. P. L. Estratégia e monitoramento em empresas startup de tecnologia - um estudo de caso. In: SIMPOSIO DE GESTÃO DA INOVAÇÃO TECNOLÓGICA, 25., Brasília, 2008. Anais... Rio de Janeiro: ANPAD, 2008. p. 1-15.

ZHUANG, L.; WILLIAMSON, D.; CARTER, M. Innovate or liquidate - are all organizations convinced? A two-phased study into the innovation process. Management Decision, v. 37, n. 1, p. 57-71, 1999. doi:10.1108/00251749910252030.

WILLIAMSON, O. E. The economics of organization: the transaction cost approach. American Journal of Sociology, v. 87, n. 3, p. 48-577, 1981. doi:10.1086/227496.
Recebido: 03/06/2012

Received: 06/03/2012

Aprovado: 04/02/2013

Approved: 02/04/2013 